\title{
Coordination of contexts and taste disagreements ${ }^{*}$
}

\author{
Coordinación de contextos y desacuerdos de gusto
}

DAVID BORDONABA PLOU**

\begin{abstract}
In this paper, I will defend that there is an asymmetry between straightforwardly factual and non-straightforwardly factual disagreements (Field 2009) in terms of persistency and retraction and that we can use what I will call 'coordination of contexts' to explain these two asymmetries. To make my point, I will focus on the kinematics of this type of disagreements. I will argue that one way to give a proper account of the kinematics of taste disagreements and to discriminate between straightforwardly factual and non-straightforwardly factual disagreements is to focus on coordination of contexts.

Keywords: Disagreement about taste; disagreement kinematics; non-straightforwardly factual disagreements; coordination of contexts; retraction.
\end{abstract}

\begin{abstract}
Resumen: En el presente artículo, defenderé que existe una asimetría entre los desacuerdos directamente factuales y los desacuerdos no directamente factuales (Field 2009) en términos de persistencia y retractación, y que podemos usar lo que denominaré 'coordinación de contextos' para explicar dichas asimetrías. Para elaborar este punto, me centraré en la cinemática de este tipo de desacuerdos. Argumentaré que una manera de explicar de manera apropiada la cinemática de los desacuerdos sobre cuestiones de gusto, a la vez que podemos distinguir los dos tipos de desacuerdos antes mencionados, consiste en centrarse en la coordinación de contextos.

Palabras clave: desacuerdos de gusto; cinemática del desacuerdo; desacuerdos no directamente factuales; coordinación de contextos; retractación.
\end{abstract}

\section{Introduction}

People with different views on humour may disagree over whether something is funny or not in the same way that people with different gustatory preferences may disagree over whether something is tasty or not. In many situations where people disagree about such matters, the use of the so-called 'taste predicates'1 provokes disagreements that are not straightforwardly factual (Field, 2009, 268, 269, 274). The following characteristics define

Recibido: 27/05/2018. Aceptado: 12/12/2018.

* This article has partly been elaborated in the framework of the project A Computational Dynamic Analysis of Public Debates on Politics, Aesthetics and Taste, funded by CONICYT FONDECYT/POSTDOCTORADO/ $\mathrm{N}^{\circ}$ Proyecto 3180096. I am grateful to Manuel de Pinedo García, María José Frápolli Sanz, Laila Miriam Jreis Navarro, Neftalí Villanueva Fernández and two anonymous referees for fruitful comments.

** David Bordonaba Plou is a FONDECYT postdoctoral researcher at the Universidad de Valparaíso, Chile. Contact: davidbordonaba@gmail.com. His most recent publications are "Desacuerdo sin Falta y Retractación: Una Defensa del Relativismo sobre Juicios de Gusto", Ideas y Valores 68, N 170 (2019): 205-228, y "Polarización como impermeabilidad: cuando las razones ajenas no importan", Cinta de Moebio 66 (2019): 295-309.

1 For the sake of economy, I will use the expression 'taste predicates' instead of 'predicates of personal taste' (Lasersohn, 2005, 644). 
a non-straightforwardly factual disagreement: i) it can persist even once the speakers involved in the disagreement made explicit their respective standards -for example, their taste standards-; ii) the disagreement is rarely resolved as a disagreement about what standard of taste should be adopted by the speakers; and iii) there could be no 'smoking guns,' no pieces of evidence that could 'settle the debate in a way that convinces all parties.' (De Cruz \& De Smedt, 2013, 173). In other words, the disagreement can be unresolvable even when all the parties involved have access to all relevant information concerning the situation. In this sense, non-straightforwardly factual disagreements are different from 'metalinguistic disagreements' (Sundell, 2011, 2016) or 'forward-looking disagreements' (Stojanovic, 2011). Let us consider the following example:

Aputsiak: Kiviak² is tasty.

Carmen: I disagree, kiviak isn't tasty.

In the example, a member of the Inuit culture and a Spaniard disagree on whether kiviak is tasty or not. This case can be understood as a case of non-straightforwardly factual disagreement because it can give rise to a persistent disagreement, it could not be solved once the speakers make explicit their standards of taste, and it is possible that no piece of evidence could settle the disagreement. We can easily imagine developments of the conversation where both parties are not willing, at least in principle, to give up their respective viewpoints towards the tastiness of kiviak. If we can imagine developments of the situation where the disagreement persists, this would occur partly because each rejects the other's stance, trying to change the other's mind.

The purpose of this paper is to defend that exists an asymmetry between straightforwardly and non-straightforwardly factual disagreements (Field, 2009) in terms of persistency and retraction and that we can use coordination of contexts to explain it. In a factual disagreement, it is easier to advocate one method for settling the disagreement. It is always possible that the two parties recognize that there could be a 'smoking gun,' a piece of evidence acknowledged by the two parties as potentially settling the debate. Besides, there seems to be an asymmetry concerning retraction. In non-straightforwardly factual disagreements, both speakers seem to be in a position to demand a retraction, unlike cases of factual disagreement where only one of the speakers may fairly demand a retraction. While, in these latter cases, both speakers may demand a retraction, it cannot be demanded in the same sense in which it is demanded in cases of non-straightforwardly factual disagreements. The factual features associated with the disagreement will make the retraction of one of the speakers consistent with the situation.

My focus in dealing with these issues will be on what speakers do when they disagree, instead of on the truth conditions of the propositions expressed by the utterances of the speakers. I will leave aside the question concerning which is the best theory to determine the truth conditions of taste judgments. An explanation focused on this would miss the proper dynamics of non-straightforwardly factual disagreements. Such an explanation would be comparative in spirit, showing the pros and cons of the different theories in competition.

2 More info: https://www.theguardian.com/tv-and-radio/2011/jan/27/tv-review-human-planet. 
Instead, I will directly address non-straightforwardly factual disagreements. I will explore this kind of disagreement and the related phenomena while attending a remarkable phenomenon, coordination of contexts. ${ }^{3}$

Disagreement is not the last stage of a conversation where a debate is taking place. On some occasions, after two speakers make their disagreement explicit, what follows is a process that allows speakers to coordinate themselves in order to make information explicit that is relevant for the disagreement. The introduction of this new information can lead speakers to shift from a situation of disagreement to a situation of agreement, or to a new situation of disagreement, that is, to a persistent disagreement. As will be pointed out below, other authors have defended similar ideas. For example, Stojanovic $(2007,2011)$ supports that taking into account considerations on how a conversation may evolve could be important to settle a disagreement. However, her proposal and the proposal defended in this work differ in various respects. For Stojanovic, there are only three possible outcomes of a taste disagreement. First, speakers realize that their argument is just a misunderstanding. Second, speakers could end up agreeing once they come to know that their tastes are different. In other words, they pass from disagreement to an agreement. Third, the conflict is a genuine disagreement where one of the parties is mistaken, thus being possible that only one of the parties demands on the other a retraction.

On the contrary, my proposal makes room for a fourth option, a non-straightforwardly factual persistent disagreement where both parties could reasonably demand a retraction. Besides, my proposal presents a mechanism, coordination of contexts, that allows us to differentiate factual disagreements from non-straightforwardly factual disagreements. Speakers involved in a factual disagreement will not persist in the disagreement after one or more coordination processes have taken place, and only one of the speakers could, in fairness, demand a retraction. However, speakers involved in non-straightforwardly factual disagreements could persist in the disagreement after one or more coordination processes have taken place, and both speakers could equally demand a retraction. Moreover, coordination of contexts helps us to describe the four possible outcomes described above.

\section{Hume on the true standard of taste}

Contrary to what seems to be a common assumption in the debate about disagreement and taste predicates, assertion and retraction conditions for these predicates are highly subject to change. Speakers using taste predicates are easily led to persistent disagreements. Can we expect to find clear resolutions for most of the situations involving this type of disagreement? Or are we condemned to endless debates when we disagree about matters of taste? Let me quote the following passage of Hume's Of the Standard of Taste to shed some light on these problematic issues:

3 My proposal on coordination of contexts is different from other proposals (MacFarlane, 2007; Marques, 2015). In those works, the coordination between speakers concerns cooperative tasks in an evolutionary framework. The coordination is borne out by the recognition of cooperation between speakers as a way to find solutions to different problems. However, in my approach, it is the disagreement that allows the coordination between speakers. 
Strong sense, united to delicate sentiment, improved by practice, perfected by comparison [emphasis added], and cleared of all prejudice, can alone entitle critics to this valuable character; and the joint verdict of such, wherever they are to be found, is the true standard of taste and beauty. (Hume, 1826, 273-274).

In this passage, Hume is talking about the requisites to acquire the true standard of taste: ${ }^{4}$ a combination of very different aspects. We can summarize them by saying that the true standard of taste requires: i) personal experience (free of prejudice), ii) improved by practice, and iii) perfected by comparison. ${ }^{5}$ The first element has been generally accepted (Gibbard, 1990, 165; MacFarlane, 2014, 4; Hirvonen, 2014, 68-69) as a necessary requisite for the rationality of assertions expressing someone's tastes. ${ }^{6}$ So, if I try a sushi dish in normal circumstances, i.e., supposing that my tasting system is not affected by unusual circumstances, and I do not like it, I am fully entitled to assert that the dish is not tasty (from now on, call this rule the PE Rule, where 'PE' stands for 'personal experience'). The importance of the second element has been recently recognized (MacFarlane, 2014; Smith, 2007, 2010). Although experiencing an object $x$, and found $x$ 's flavor pleasant, is a solid reason for considering that people are entitled to say that $x$ is tasty, people try to refine their taste through practice. Consider the amount of tasting courses offered today: wine, beer, olive oil, coffee, or chocolate tasting courses, to name just a few. Finally, the third factor has been frequently overlooked. We disagree about many matters, but the disagreement can acquire a different dimension when taste predicates are at stake. If I disagree with someone on whether something is tasty or not, our disagreement may not be so easily solved. Our disagreement could be non-straightforwardly factual. In these cases, the importance of engaging with other people in a process where our reasons to support our assertions are evaluated is crucial. Disagreeing with other people is not just asserting contrary propositions, it is also a way to evaluate our reasons, and, as Hume says, to perfect them comparing them with other's reasons.

In short, although to have personal experience of something we find pleasant to taste is enough to be entitled to assert that something is tasty, we often seek to improve our acquaintance with that object through practice. Besides, we also may be prepared to evaluate it through disagreement. All these elements are interrelated and are complementary. To have personal experience of an object $x$, where $x$ 's flavor is found pleasant, is the minimum requirement to be entitled to assert that something is tasty. However, many people are disposed to educate their taste through practice. Besides, we can be prone to confront our assessment with that of other people. Disagreement is not only a situation in which two people exhibit their contrary opinions, but it is also a process of expressing our reasons, prejudices, and cultural conditioning to other people.

4 In this paper, I support the idea that, for humans, the only way to achieve something similar to the true standard of taste is by taking part in meaningful debates where both parties evaluate the strength of their reasons.

5 The accuracy of the historical interpretation of Hume's philosophy is not addressed here. I am just taking Hume as a source of inspiration for making my point clearer.

6 Meskin and Robson (2015) argue that direct acquaintance with the object being experienced is not necessary. They rely on cases of 'taste-imony', i.e. cases of pure testimony about matters of taste. Although this deserves close attention, evaluating their arguments is beyond the scope of this paper. 


\section{Disagreement kinematics}

As stated in the Introduction, a situation of disagreement could not be the last stage in a conversation. A widespread understanding of disagreement has been 'The Simple View of Disagreement' (MacFarlane, 2014, 121) or 'Content Disagreement' (Sundell, 2011, 275). This specific understanding places the focus on a specific mark of disagreement, the contradictory truth-values of the contents asserted by the speakers. Recently, some authors (Sundell, 2011; Huvenes, 2012, 2014; MacFarlane, 2014; López de Sa, 2015) have argued that The Simple View of Disagreement is not the only way to look at the ordinary notion of disagreement. I will follow this line of thought. Besides, I will focus on longer pieces of discourse. The examples depicting disagreement scenarios (Lassersohn, 2005; Glanzberg, 2007; Huvenes, 2012, 2014; MacFarlane, 2014; López de Sa, 2015) usually consist of one speaker saying $p$ and the other speaker saying $q$ (where $q$ logically implies not- $p$ ). Such examples make it impossible to illustrate persistent disagreements. The examples-style I follow can be found in other authors (Stevenson, 1944/1960; Schaffer, 2011; Blome-Tillmann, 2014).

A disagreement can develop in many different ways. On many occasions, these ways are indispensable for understanding the kind of disagreement that is at stake, whether straightforwardly factual or not. For example, Stojanovic (2007) argues that we should pay due attention to the kinematics of disagreement. This author argues that all cases of disagreement are either cases of genuine disagreement or plain misunderstandings. She presents an example where two people are talking about soybean ice-cream, and one says that the ice-cream is delicious and the other contends that the ice-cream is not delicious. This example is like other typical examples, except that a suggestive passage follows it:

I will try to show that considerations about the context in which the dialogue arises, and about the ways in which it may evolve [emphasis added], make it possible to decide whether we have a case of genuine disagreement, or only disagreement due to a misunderstanding. (Stojanovic, 2007, 693)

Stojanovic (2007) highlights several ways in which a disagreement could evolve. One option is that, once both speakers have made it explicit that their taste standards differ, they recognize that they are now agreeing, they have 'moved from 'Oh yes/Oh no' dialogue to 'Ok/Ok' dialogue' (Stojanovic, 2007, 694). For the author, two people who have expressed a difference in their tastes should realize that 'their seemingly contradictory utterances may be simultaneously true' (Stojanovic, 2007, 694). However, although there are situations where two people end up agreeing once they have made their divergence in taste explicit, there are other situations where both parties persist in disagreeing. I will defend that persistent disagreements are also a possibility. Sometimes, people persist in disagreeing even when all relevant features concerning the situation have been made explicit. The author explicitly recognizes this option. She thinks people may engage in persistent disagreements. As one of her examples shows, one speaker could say that soybean ice-cream is delicious tout court. The argument continues that when speakers assert that something is tasty tout court, they are saying that the dish is tasty 'on some universally or at least generally accepted standards' (Stojanovic, 2007, 694). That is, the two parties disagree on whether the soybean ice-cream 
is delicious or not for most people. As so presented, these would be cases of factual disagreement because we would then have a method to determine which party is mistaken: we would have to determine, for example, by a survey, as the author suggests, whether the thing is tasty for most people or not.

Even assuming that such a method would work sufficiently well to test different gastronomic cultures, I do not think that it solves the issue. In this work, I defend that a good standard of taste is one that follows Hume's recipe: personal experience (free of prejudice), improved by practice, and perfected by comparison. Applying the method suggested by Stojanovic to the kiviak case will bring a clear outcome: kiviak is not tasty because it is not tasty for most people. However, this outcome is unacceptable. A general survey does not resolve some persistent disagreements. In fact, people should not resolve some persistent disagreements appealing to methods such as the above mentioned. For example, in the kiviak case, Aputsiak would be right in persisting in the disagreement even once he comes to know that most people think that kiviak is not tasty. He is just trying that Carmen leaves aside her cultural prejudices. He only wants to reach a kind of "middle ground." The partial or complete agreement is still far away, but the persistence in disagreeing on the part of Aputsiak is worth taking, at least in this case. Neglecting the possibility of significant persistent disagreements like (1)-(2) is dangerous because we deny ourselves the possibility of expressing our reasons, prejudices, and cultural conditioning to other people.

Despite the differences, there are several commonalities between the approach sketched and my own. First, how a conversation evolves can be relevant to determine the existence of disagreement. I agree with the author that many disagreements can be just misunderstandings or cases of factual disagreement. However, non-straightforwardly factual disagreements are a possibility as legitimate as misunderstandings and straightforwardly factual disagreements. My approach is complementary to the one depicted above. One of the tasks performed by early coordination processes is precisely making explicit relevant information for solving possible misunderstandings. If there are no misunderstandings, the outcome of other coordination processes could be that speakers realize that they are in a straightforwardly factual disagreement. If there is still an impression of disagreement between both parties, then the disagreement is non-straightforwardly factual.

\section{The Three-Level Picture}

Once having seen the different ways in which taste disagreements could evolve, I will now bring together the different features involved in this kind of disagreements. I will focus on representing how it is for a speaker to disagree with another speaker about such matters. This will be presented as a complex experience with three different levels:

- Factual level (the bottom level): it includes the physical features of the object being experienced. If, for example, we are eating sushi, the factual elements would be the type of rice, the type of fish, the cooking point of the rice, or the type of mirin, whether mirinfuhmi or hon-mirin, used on the rice. This level is factual because the features or properties that are relevant for saying that something is tasty are the same for all possible experiencers. However, all factual features being equal for both speakers is not sufficient to result in a 
similarity in taste. Sometimes, speakers pay attention to different factual features, and this can provoke a disagreement. For example, two different speakers can disagree on whether salmon spawn are tasty or not, depending on whether the spawns are eaten on a toast or in a piece of maki sushi.

- Awareness level (the middle level): in the example we began with, Aputsiak and Carmen know that they disagree on whether kiviak is tasty because they make mutually incompatible assertions. In the first step of a disagreement, the two parties realize their assertions are mutually incompatible. This represents an important point in a disagreement, as many authors testify (Lassersohn, 2005; Glanzberg, 2007; Huvenes, 2012, 2014; MacFarlane, 2014; López de Sa, 2015), but, in this paper, it will be the starting point. Since non-straightforwardly factual disagreements can be persistent, speakers can assert something that adds new information to the context. These assertions are a way for speakers to "update" the context if they think this information can have a direct impact on the disagreement. The outcomes of this updating vary. Speakers can switch from disagreement to agreement. Some authors (MacFarlane, 2007; Marques, 2015) have given prominence to agreement instead of disagreement. They say, agreement in taste 'enables further cooperation and altruistic behaviour, and is more likely to lead to future benefits' (Marques, 2015, 9). However, speakers can also shift from disagreement to a new situation of disagreement. Although agreement in matters of taste has undoubtedly played an adaptive role in human evolution, disagreeing with other people is also a source of coordination, since it is a way to test our standards. In these cases, the awareness level is even more critical because speakers will "update" the context more frequently. In sum, the awareness level is present whenever speakers realize that they are in disagreement, or whenever they made explicit information that could change the outcome of the conversation.

- Normative level (the top level): there are invariably rules associated with the use of taste predicates. The default rule is the PE rule, but there can be other types of rules involved: ethical, social, or cultural rules. When speakers use taste predicates, they express their appro$\mathrm{val} /$ disapproval of some foods, but they also express the acceptance of rules. For example, for the Inuit Aputsiak, there are social rules involved. Although kiviak may look like an unappetizing dish for non-Greenlanders, it is perhaps their most culturally identifying meal, now in vogue, and therefore it is frequently served on Christmas Eve. On the contrary, for the Spaniard Carmen, tradition plays a lesser role in her judgment, but rules of hygiene do. This does not mean that tradition plays no role. It is just an idealization for the sake of the argument intended to highlight the relevance of certain rules for the Spaniard concerning the manufacturing and processing of food. Such policies have been vital in Europe, for instance allowing societies to avoid the spread of certain diseases.

In the next section, I will explore the interplay between the three levels. On the one hand, a disagreement between two speakers can be based on the factual level, because it depends on factual properties. On the other hand, a disagreement between two speakers can be based on the normative level, because the rules underlying the approval/disapproval are different. In this second case, I will show how other rules besides the PE Rule are relevant in determining the assertion conditions of taste predicates. 


\section{Coordination of contexts}

Taste predicates are unique in their class. Their assertion and retraction conditions are highly subject to change, even when minor changes occur. I will argue that propositions involving taste predicates can give rise to non-straightforwardly factual disagreements and that the presence of coordination processes is a distinctive mark of the persistency. The disagreement appears when one speaker makes a statement, and then the other speaker makes another statement that is incompatible with the former. At this stage, the only level we need to explain the disagreement is the awareness level. Both speakers know that the contents expressed by their utterances are incompatible, and this is an essential part of the phenomenon, but we should not let this intuition conceal other factors that could play an active role in the disagreement. Speakers could say something that adds new information to the context, thus bringing into play the other levels.

In this section, I will expound two different coordination processes: bottom-up and top-down. In addition, I will discern several possible scenarios produced by coordination processes: speakers involved in a bottom-up coordination process can realize that the disagreement is a simple misunderstanding, a factual disagreement or a non-straightforwardly factual disagreement; and speakers involved in a top-down coordination process can realize that the disagreement is a non-straightforwardly factual disagreement.

\subsection{Bottom-up coordination processes}

In bottom-up coordination, certain factual elements that are relevant for a disagreement are made explicit in the context. As the next three examples will show, if bottom-up coordination processes take place, speakers can realize whether they are facing a case of misunderstanding, a factual disagreement, or a non-straightforwardly factual disagreement. A suitable example of the first is the following: consider three friends on holiday in Japan eating sushi at a restaurant. A and B are talking to each other comparing the sushi they are eating with the sushi they ate the previous day, but $\mathrm{C}$ is not paying too much attention to the conversation:

3) A: The sushi [Talking about sushi (the sushi they ate yesterday)] was good.

4) B: Yes, you're right. One of the best sushi I've ever tried.

5) C: Are you mad? This sushi [talking about sushi 2 (the sushi they are eating now)] is awful. How can you say it's the best sushi you've ever tried?

6) A: Have you heard anything? We weren't talking about this sushi, but about the sushi we ate yesterday. In fact, we've already said that this sushi is awful.

7) C: Ah, ok. Yeah, yesterday's sushi was excellent.

From (3) to (5), the only level that is required to make sense of the situation is the awareness level. A and B agree on whether sushi $i_{1}$ is tasty, but they disagree with $\mathrm{C}$. However, after the coordination process, the factual level comes into picture because of A in (6) "update" the context highlighting that $\mathrm{C}$ is mistaken about one factual element: the sushi they are talking about. After that, they realize that the contents expressed by their utteran- 
ces are consistent. They agree both that sushi $i_{1}$ is tasty and that sushi $i_{2}$ was not tasty. The apparent disagreement is a simple case of misunderstanding because they are talking about different sushi. Early bottom-up coordination processes can help speakers to realize that the disagreement is only apparent.

However, there are other possible outcomes of a bottom-up coordination process: speakers can understand that the disagreement is factual. Let us consider, for example, people disagreeing about the amount of one ingredient in a given dish (a load of pepper or just a pinch), or what kind of pepper is in a dish, whether green or red. These disagreements are based only on factual properties, so it should always be possible to consider some evidence to resolve the dispute. Suppose that one says that the dish is seasoned with curry, and the other says that the dish is seasoned with turmeric. They disagree, but their disagreement can be solved if, for example, they ask the waiter what type of spice has been used. Regardless, what is clear is that there is no reason for them to persist in the disagreement once they have applied a method to identify the seasoning of the dish unless they are irrational. One of them has to be mistaken, so only one can demand a retraction on the other part. Alternatively, maybe both are mistaken if, for example, the chef has used neither of the spices. To see this as clearly as possible, let us consider the next example, where two people eating at a Thai restaurant are arguing on whether the curry they are eating is red or green curry:

8) A: There's only a pinch of curry in the dish, but I think it's green curry.

9) B: That's false, it's red curry.

10) A: I think you're wrong. It's unmistakable because of the spicy taste.

11) B: I don't think so, I think it's red curry. I suppose you know that red curry is made of red peppers and green curry is made of green peppers. So, the spicy taste isn't telling at all. Maybe red peppers aren't as spicy as green ones, but they're spicy enough to make a difference.

12) A: I know that, but you're totally wrong. Anyway, it's easy to know what type of curry the chef has used. I'm going to ask the waiter.

13) Yeah, of course.

In (8)-(9), the two speakers disagree on whether it is red or green curry on the dish. For now, the only level that is necessary to account for the scenario is the awareness level. In (10)-(11), they make explicit factual information that is relevant for the discussion. At this point, the factual level is necessary to make sense of the situation, since the context has been "updated" with new factual information. However, in the end, as it is suggested in (12)-(13), only one of them can be right. Let us assume that the chef has used only red curry in the dish. As soon as they find this out, A should recognize the mistake. Again, the awareness level would be in the picture because now speakers know that one of them is mistaken. In summary, bottom-up coordination processes allow speakers to specify factual features involved in the disagreement. Once these features are made explicit, the speakers can recognize that the disagreement is a case of misunderstanding or a factual disagreement, as in (3)-(7) and (8)-(13), respectively. 
However, there is still another possibility: speakers realize that their disagreement is not going to be easily solved. The final example of this section aims to show that the outcome of a bottom-up coordination process can be a persistent disagreement. Sometimes, speakers make explicit factual information that is relevant for the disagreement, information all speakers are aware of, but this does not help in any sense to solve the dispute. Instead, the speakers involved tend to entrench themselves, thus persisting in disagreeing. Consider the next excerpts from a conversation on Reddit ${ }^{7}$ regarding if putting breadcrumbs makes meatballs tastier:

14) A: Does anyone else not put bread crumbs or other fillers in their meatloaf, meatballs, similar? It's just the way my mom always made these kinds of dishes, she never added bread crumbs and other fillers to them. They don't fall apart either with egg. Still have spices and seasonings though.

15) B: I do, and sometimes I don't. Usually I add it because it makes for more juicy meatballs, not because it acts as a filler. Pure meat meatballs can be very dense and chewy.

16) C: Meatballs and meatloaf really benefit from breadcrumbs. It soaks up all the juice that would otherwise leak out.

17) D: It's a binder, not a filler.

18) A: It doesn't fall apart without it so...? I guess it's optional.

19) E: I mean, most things are optional in cooking - it's about what you like to eat. That said, bread in meatballs is about texture and, most importantly, flavor.

20) D: A filler is used as a substitute or to stretch out an ingredient, usually due to cost.

21) A: I know.

22) F: Why do you think these recipes were invented? To stretch meat. It also adds wonderful texture and moisture.

23) A: I know.

24) G: My mom never used bread crumbs either. Always juicy and tender meatloaf with nothing falling apart. Breadcrumbs just seems like what people are used to but unnecessary.

25) A: Seems like it. I think they used to add it to increase amount, I think it originated during WW2. Anyways, that's what I was told.

A starts the conversation, probably, looking for support. A's mom does not use breadcrumbs in her meatballs, and he or she wants to know if there are other people that neither use it. However, as the conversation goes, many people recommend using breadcrumbs in meatballs. They do not act as a filler, as A believes, but as a binder, making the meatballs more consistent. Besides, it brings to the mixture a nice texture and moisture. In doing so, they add factual information that is relevant to the discussion. At this point, the factual level is necessary to illustrate the situation since new factual information has been added to the context. A seems to accept the idea that breadcrumbs not only act as a filler, responding

7 https://www.reddit.com/r/Cooking/comments/9o0ytl/does_anyone_else_not_put_bread_crumbs_or_other/. 
twice 'I know' to comments from D and F. Now, we need not only the factual level but also the awareness level. A has made explicit the acceptance of the information, so D and F could demand a retraction from A. However, in the end, G supports A's initial stance, and $\mathrm{A}$ ends up disagreeing with the other speakers. He or she states that breadcrumbs are used only as a filler, a practice originated in World War II. It seems plausible that A, being reinforced by G's opinion, could demand a retraction from D and F at this stage of the conversation. In the end, it seems rational that the two parties in the disagreement, those who think that breadcrumbs are necessary and those who do not, can reasonably demand a retraction on the other part.

In sum, although the coordination process makes factual information explicit, the character of the disagreement is non-straightforwardly factual because the speakers end up disagreeing even once they have made explicit factual information that has a direct impact on the disagreement. If D and F read A's last remark, they would respond thus prolonging the debate, and the awareness level would be necessary again because $\mathrm{D}$ and $\mathrm{F}$ would be indicating that they are again in disagreement with A.

\subsection{Top-down coordination processes}

As noted above, there can be disagreements that do not depend only on factual elements. The previous section showed the different outcomes a bottom-up coordination process could have. In this section, I will explain the other kind. Top-down coordination specifies rules that have a direct impact on the disagreement. The PE Rule is the rule functioning by default. In other words, PE is the rule sanctioning gustatory experiences in most situations. Nevertheless, there are other cases in which other rules can override it. The idea of top-down effects is not a new one. In the debate on 'cognitive penetration's many authors (Nanay, 2014, 2016; Stokes, 2014; Vetter \& Newen, 2014; Silins, 2016) defend an influence from higher to lower levels. Specifically, cognitive processes such as 'learning, memorizing, imagining, attending, considering, decision making, linguistic expression' (Vetter \& Newen, 2014, 63) can affect the most basic levels of perception. Most of the work in this field focuses on visual perception. However, if memory, cultural background, or even emotions influence what we directly see, why could it be not possible that social, cultural, or ethical rules influence our perception when we eat something? Some work is devoted to showing top-down effects on taste experience. For example, Silins (2016) says that 'the information that a beer contains vinegar changes your taste experience rather than merely changing your evaluation in judgment of the taste experience.' In a similar vein, I will defend that ethical, social, or cultural rules, or even expectations or emotions related to this kind of rules, can affect our taste experience. The advantage of my approach over other explanations is that it can account for those cases in which the assertion conditions of taste predicates are determined by more than one rule. Now, I will present some examples showing how top-down coordination allows speakers to specify rules that are relevant for saying that something is tasty. Consider two people eating in a restaurant in Japan and trying a new dish:

8 I am indebted to an anonymous referee for this comment. 
26) A: Ummm, it's really tasty.

27) B: Yeah, you're right.

28) A: I wasn't sure at first because it's whale meat, but it's really good.

29) B: Whale meat? Ugh, this isn't tasty anymore.

30) A: What's the problem? I thought you've liked its flavour.

31) B: Its flavour? Are you kidding me? I cannot understand how you can say that it's tasty after knowing the dish is made of whale.

32) A: Well, it's still delicious. I understand the problem of eating protected species and all that stuff, but I don't really see what that has to do with the dish being delicious.

As seems apparent, A and B do not disagree in (26)-(27). The flavour of the sushi is pleasing for both speakers, so, according to PE, both of them should call the sushi 'tasty'. However, when new information is added to the context by A, the fact that they are eating whale meat, they suddenly disagree. The updating of the context has prompted a change of mind of B. The sushi is disgusting now since it is sushi from a protected species. The rule that appears to be in command now is not PE, but a new rule we can call $\mathrm{PE}^{*}$ : call it 'tasty' if you know it first-hand and you like it unless it is a protected species that you are eating. PE is no longer in place after the change of context. When B realizes that it is whale meat, experiencing a delicious sensation is not enough to call the dish 'tasty'. Once this new rule is in place, whether the piece of fish that B is eating is pleasant or not becomes irrelevant, 'it's tasty' is no longer appropriate to say. The rule endorsing the experience of $\mathrm{B}$ has changed, thereby changing the taste standard of $\mathrm{B}$ : this speaker no longer thinks that it is correct to describe this sushi as tasty; the new rule, $\mathrm{PE}^{*}$, does not back this course of action. Note that the rule discrediting the experience could have been a different one. For example, B could have had a similar change of mind on considering it wrong to eat intelligent species or for the love of whales. The following example illustrates this latter point. Let us retake the example we began with, where Aputsiak and Carmen were trying kiviak:

33) Apustsiak: Ummm, kiviak's so tasty.

34) Carmen: I disagree, kiviak isn't tasty.

35) Aputsiak: Ok, it may look repulsive, but you must recognize that the flavour is really good.

36) Carmen: Sorry, but the flavour isn't good at all.

37) Aputsiak: Since you've had the courage to try it, I thought you'd be more openminded. Your cultural prejudices are fooling you.

38) Carmen: I've agreed to try it because I don't like to reject something without trying it, especially if it's important for a culture. I think that should keep me from being called intolerant. Anyway, it isn't only the awful flavour, or the fact that it is liquefied bird innards. This stuff is rotten. It's dangerous.

Unlike the whale-sushi case, in the kiviak example, 'tasty' seems not to correspond to ethical rules but to another type of rules. Expectations and emotions related to social and 
cultural rules seem to be involved. For Aputsiak, their cultural and educational background exerts a strong influence. To call the kiviak 'tasty' is not only to express his taste but to defend part of his culture. For Carmen, there seem to be social implications to discourage the eating of rotten food. In general, cultural and educational background exerts a strong influence on people's tastes, and the persistence of non-straightforwardly factual disagreements shows this. Is it wrong for a member of the Inuit culture to keep insisting that kiviak is tasty? I would say that it depends on the consistency of their reasons and the amount and character of their prejudices. How can we evaluate them? Just as Hume says, perfecting them by comparison, engaging in disagreement with other people.

\section{The master and the slave}

Disagreeing with other people is not just asserting contrary propositions. Uttering propositions with incompatible contents is not enough to understand a situation of persistent disagreement. In this section, I want to suggest that another ingredient is indispensable for the persistent disagreement recipe: not to exhibit a live-and-let-live attitude towards the preferences of the other party in the disagreement. If both speakers show a live-and-let-live attitude, they will tend to adopt a neutral or non-confronting attitude. To shed some light, let me quote the next passage from Lewis (1979):

For some reason -coercion, deference, common purpose- two people are both willing that one of them should be under the control of the other. Call one the slave, the other the master. The control is exercised verbally, as follows.

At any stage in the enslavement, there is a boundary between some courses of action for the slave that are permissible, and others that are not. The range of permissible conduct may expand or contract. (Lewis, 1979, 340)

In a conversation between two people, there can be one master and one slave, two slaves or two masters. The master determines what courses of action are permissible, and the slave makes a behavioural adjustment to fit the master's dictates. If we consider the whale-sushi case, in the beginning, both speakers agree on the sushi being tasty. It could be said that neither of them has adopted the master role yet. However, when A "updates" the context adding the information 'whale meat', B feels forced to assume the master role and states that calling a whale sushi 'tasty' is not a permissible course of action, thus being possible that $\mathrm{B}$ demands a retraction.

Similarly, A adopts also the master role, disagreeing with B, and being equally possible to demand a retraction. In a non-straightforwardly factual disagreement, in a persistent disagreement, there are two masters, and nobody is making a behavioral adjustment to resolve the situation. If one of them at one stage of the conversation makes a retraction, thus becoming the slave and fitting the master's dictates, then the disagreement is resolved. However, who adopts the master or the slave role will depend on whether either speaker adopts a live-and-let-live attitude. As Field says, in a dispute about taste, what makes a difference in setting up the disagreement has 'to do with the extent to which one takes a live-and-let-live attitude to the other's preferences, which in turn is in part due to the 
impact of his acting on those preferences on one's own concerns ...' (Field, 2009, 277). It is not merely a matter of how critical a person is when engaging in a disagreement. A critical person is indeed more prone to disagree than a non-critical person, but it also depends on the issue that people disagree about. If the speakers do not show a live-andlet-live attitude, a disagreement can arise. However, not adopting this attitude depends on how much the issue matters. One person may show a live-and-let-live attitude if the other party is expressing personal preferences and, for example, utters 'I like peanuts'. However, if someone say 'Whale sushi is tasty', there are more reasons for not adopting a live-and-let-live attitude. This is not a matter of personal preference, because an ethical rule is relevant for the disagreement. Depending on several factors, such as the dish being eaten or the manufacturing processing, people will feel more compelled not to adopt a liveand-let-live attitude, thereby assuming the master's role. The consequences of applying the predicate 'tasty' are not the same when we are eating peanuts, sushi without wasabi, whale sushi, rabbits, dogs, cats, animal foetuses, or humans.

In conclusion, the master/slave metaphor gives us an excellent insight to understand some aspects of non-straightforwardly factual disagreements. It bears considering cases in which both speakers adopt the master role -that is, cases in which both speakers seek to set the standard for different courses of action-. In disagreements that are not straightforwardly factual, this situation seems very common.

\section{Conclusion}

I have argued for an asymmetry between straightforwardly and non-straightforwardly factual disagreements. In the latter, but not in the former, the disagreement can be persistent. Besides, both speakers can fairly demand a retraction. In order to explain certain features of this kind of disagreement, it is crucial to attend to the proper kinematics of nonstraightforwardly factual disagreements. I have defended the need to consider a particular phenomenon to accomplish this task: coordination of contexts. Coordination of contexts enables speakers involved in a disagreement to make certain information explicit. Bottomup coordination makes factual information explicit. Top-down coordination specifies rules other than the PE Rule that cause an impact on the assertion conditions of taste predicates. When a coordination process takes place, different outcomes can follow. It can eliminate certain misunderstandings, and it can make speakers realize what kind of disagreement they are taking part in, whether straightforwardly factual or not.

Besides, an approach that considers such a phenomenon can also account for cases in which speakers "update" the context with new information, for example, by introducing rules that are making an impact on the situation of disagreement. A speaker can express approval of a dish under the rule PE, but another speaker could approve of the same dish under PE*. The food that speakers should call tasty is determined by a great variety of rules. The approach depicted in this paper can also account for cases in which other rules are governing the disagreement. 


\section{References}

BLOME-TILLMANN, Michael (2014): Knowledge and presuppositions, Oxford University Press, Oxford.

DE CRUZ, Helen \& DE SMEDT, Johan (2013): «The value of epistemic disagreement in scientific practice. The case of Homo Floresiensis», Studies in History and Philosophy of Science, Part A, no 44(2), pp. 169-177.

FIELD, Hartry (2009): «Epistemology without metaphysics», Philosophical Studies, $\mathrm{n}^{\circ} 143$, pp. 249-290.

GIBBARD, Alan (1990): Wise choices, apt feelings, Oxford University Press, New York.

GLANZBERG, Michael (2007): «Context, content, and relativism», Philosophical Studies, $\mathrm{n}^{\mathrm{o}} 136(1)$, pp. 1-29.

HIRVONEN, Sanna (2014): Predicates of personal taste and perspective dependence, $\mathrm{PhD}$ thesis, UCL.

HUME, David (1826): «Of the standard of taste», in The philosophical works of David Hume, vol. 3, A. Black and W. Tait, Edinburgh, pp. 256-282.

HUVENES, Torfinn T. (2012): «Varieties of disagreement and predicates of taste», Australasian Journal of Philosophy, $\mathrm{n}^{\circ}$ 90(1), pp. 167-181.

HUVENES, Torfinn T. (2014): «Disagreement without error», Erkenntnis, no 79, pp. 143154.

LASERSOHN, Peter (2005): «Context dependence, disagreement, and predicates of personal taste», Linguistics and Philosophy, $\mathrm{n}^{\circ} 28$, pp. 643-686.

LEWIS, David (1979): «Scorekeeping in a language game», Journal of Philosophical Logic, $n^{\circ} 8(1)$, pp. 339-359.

LÓPEZ DE SA, Dan (2015): «Expressing disagreement: a presuppositional indexical contextualist relativist account», Erkenntnis, n 80 , pp. 153-165.

MACFARLANE, John (2007): «Relativism and disagreement», Philosophical Studies, $\mathrm{n}^{\circ}$ 132(1), pp. 17-31.

MACFARLANE, John (2014): Assessment-sensitivity: Relative truth and its applications, Oxford University Press, New York.

MARQUES, Teresa (2015): «Disagreeing in context», Frontiers in Psychology, n ${ }^{\circ}$, pp. $1-12$.

MESKIN, Aron \& ROBSON, Jon (2015): «Taste and acquaintance», The Journal of Aesthetics and Art Criticism, n ${ }^{\circ}$ 73(2), pp. 127-139.

NANAY, Bence (2014): «Cognitive penetration and the gallery of indiscernibles». Frontiers in psychology, 5, 1527, 10.3389/fpsyg.2014.01527.

NANAY, Bence (2016): Aesthetics as philosophy of perception, Oxford University Press, Oxford.

RECANATI, Francois (2004): Literal meaning, Cambridge University Press, New York.

SCHAFFER, Jonathan (2011): «Perspective in taste predicates and epistemic modals», in: A. Egan and B. Weatherson (eds.): Epistemic modality, Oxford University Press, Oxford, pp. 179-226.

SILINS, Nicholas (2016): «Cognitive penetration and the epistemology of perception», Philosophy Compass, $\mathrm{n}^{\mathrm{o}}$ 11(1), pp. 24-42. 
SMITH, Barry C. (2007): «The objectivity of tastes and tasting», in: B. C. Smith (ed.): Questions of taste: The philosophy of wine, Signal Books Limited, Oxford, pp. 61-101. SMITH, Barry C. (2010): «Relativism, disagreement and predicates of personal taste», in: F. Recanati, I. Stojanovic \& N. Villanueva (eds.): Context-dependence, perspective and relativity, Mouton de Gruyter, Göttingen, pp. 195-224.

STEVENSON, Charles L. (1944/1960): Ethics and language, Yale University Press, New Haven.

STOKES, Dustin (2014): «Cognitive penetration and the perception of art», Dialectica, ${ }^{\circ}$ 68(1), pp. 1-34.

STOJANOVIC, Isidora (2007): «Talking about taste: Disagreement, implicit arguments, and relative truth», Linguistics and philosophy, $\mathrm{n}^{\circ}$ 30(6), pp. 691-706.

STOJANOVIC, Isidora (2011): «When (true) disagreements give out», Croatian Journal of Philosophy, $\mathrm{n}^{\circ}$ 11(2), pp. 183-195.

SUNDELL, Timothy (2011): «Disagreements about taste», Philosophical Studies, $\mathrm{n}^{\circ} 155(2)$, pp. 267-288.

SUNDELL, Timothy (2016): «The tasty, the bold, and the beautiful», Inquiry: An Interdisciplinary Journal of Philosophy, $\mathrm{n}^{\circ}$ 59(6), pp. 793-818.

VETTER, Petra \& NEWEN, Albert (2014): «Varieties of cognitive penetration in visual perception», Consciousness and Cognition, $\mathrm{n}^{\circ} 27, \mathrm{pp} .62-75$. 